\title{
The benefit of limb cloud imaging for infrared limb sounding of tropospheric trace gases
}

\author{
S. Adams ${ }^{1,2}$, R. Spang ${ }^{1}$, P. Preusse ${ }^{1}$, and G. Heinemann ${ }^{2}$ \\ ${ }^{1}$ Institute of Chemistry and Dynamics of the Geosphere (ICG) I, Forschungszentrum Jülich, Jülich, Germany \\ ${ }^{2}$ Department of Environmental Meteorology, University of Trier, Trier, Germany
}

Received: 17 January 2009 - Published in Atmos. Meas. Tech. Discuss.: 2 March 2009

Revised: 25 May 2009 - Accepted: 31 May 2009 - Published: 22 June 2009

\begin{abstract}
Advances in detector technology enable a new generation of infrared limb sounders to measure 2-D images of the atmosphere. A proposed limb cloud imager (LCI) mode will detect clouds with a spatial resolution unprecedented for limb sounding. For the inference of temperature and trace gas distributions, detector pixels of the LCI have to be combined into super-pixels which provide the required signal-to-noise and information content for the retrievals. This study examines the extent to which tropospheric coverage can be improved in comparison to limb sounding using a fixed field of view with the size of the super-pixels, as in conventional limb sounders. The study is based on cloud topographies derived from (a) IR brightness temperatures (BT) of geostationary weather satellites in conjunction with ECMWF temperature profiles and (b) ice and liquid water content data of the Consortium for Small-scale Modeling-Europe (COSMO-EU) of the German Weather Service. Limb cloud images are simulated by matching the cloud topography with the limb sounding line of sight (LOS). The analysis of the BT data shows that the reduction of the spatial sampling along the track has hardly any effect on the gain in information. The comparison between BT and COSMO-EU data identifies the strength of both data sets, which are the representation of the horizontal cloud extent for the BT data and the reproduction of the cloud amount for the COSMO-EU data. The results of the analysis of both data sets show the great advantage of the cloud imager. However, because both cloud data sets do not present the complete fine structure of the real cloud fields in the atmosphere it is assumed that the results tend to underestimate the increase in
\end{abstract}

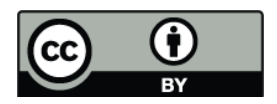

Correspondence to: $\mathrm{S}$. Adams (susanne.adams@uni-trier.de) information. In conclusion, real measurements by such an instrument may result in an even higher benefit for tropospheric limb retrievals.

\section{Introduction}

Limb sounding of infrared emissions from satellites has made a great contribution to our understanding of the middle atmosphere. Infrared limb sounders measure temperatures and a variety of trace gases at good vertical resolution and nearly global coverage. This makes them ideally suited for studies of planetary scale waves such as Rossby waves (e.g. McIntyre and Palmer, 1984; Riese et al., 2002), tropical wave modes (e.g. Canziani, 1999; Smith et al., 2002; Ern et al., 2008) and tides (e.g. Ward et al., 1999; Zhang, 2008). They have been used to quantify cross-latitudinal transport by streamers and filaments (e.g. Offermann et al., 1999; Schaeler et al., 2005; Konopka et al., 2005), to more closely determine the age of air (Stiller et al., 2008) and middle atmosphere chemistry (e.g. Kuell et al., 2002). In addition, they enable regions of enhanced tropospheric pollution to be identified (Stiller et al., 2007).

Limb sounders were also employed to study mesoscale processes. In the upper troposphere and lower stratosphere (UTLS) filaments become remarkably long $(\sim 10000 \mathrm{~km})$ and narrow $(\sim 100 \mathrm{~km})$ (Bacmeister et al., 1999; Konopka et al., 2005). Stratosphere-troposphere exchange (STE) processes such as cut-off lows with diameters of less than $1000 \mathrm{~km}$ were observed as they evolve in time and form filaments (Offermann et al., 2002). The Limb Infrared Monitor for the Stratosphere (LIMS) was the first instrument to study gravity waves (GWs) from space (Fetzer and Gille, 1994).

Published by Copernicus Publications on behalf of the European Geosciences Union. 
Table 1. Sampling of the infrared limb imager.

\begin{tabular}{lrrr}
\hline $\begin{array}{l}\text { Sampling } \\
\text { Mode }\end{array}$ & $\begin{array}{r}\text { Vertical } \\
{[\mathrm{km}]}\end{array}$ & $\begin{array}{r}\text { Across-track } \\
{[\mathrm{km}]}\end{array}$ & $\begin{array}{r}\text { Along-track } \\
{[\mathrm{km}]}\end{array}$ \\
\hline $\begin{array}{l}\text { Dynamics mode } \\
\text { (D-mode) }\end{array}$ & 0.5 & 24 & 50 \\
$\begin{array}{l}\text { Chemistry mode } \\
\text { (C-mode) }\end{array}$ & 2.0 & 80 & 80 \\
$\begin{array}{l}\text { Limb cloud imager } \\
\text { (LCI) }\end{array}$ & 0.5 & 4 & 8 \\
\hline
\end{tabular}

In addition, recent progress has been made in the analysis of cloudy IR spectra with respect to radiative transport modelling and cloud parameter retrieval (Höpfner, 2004; Ewen et al., 2005), and especially for the detection and classification of polar stratospheric clouds (PSC) (Spang and Remedios, 2003; Höpfner et al., 2006).

All these processes have in common that, though they are of mesoscale, they influence or even control the global state of the atmosphere. The above-mentioned and those following on from them were successful in providing constraints for exchange processes, gravity waves, air pollution and clouds for the whole globe. However, it also became evident that the horizontal sampling was not really sufficient for these mesoscale processes. Making use of recent developments in detector technology adequate horizontal sampling is feasible for future missions. Instead of subsequently sampling the various altitudes, this new generation of instruments will obtain 2-D images of the limb instantaneously like a CCD camera, but will at the same provide spectral resolution. A detailed technical description of such an instrument is given by Friedl-Vallon et al. (2005). The instrument parameters studied here are chosen in accordance with the mission requirements defined in the PREMIER assessment report (ESA, 2008). The size of a single detector pixel corresponds to $500 \mathrm{~m}$ in the vertical and $4 \mathrm{~km}$ in across-track direction. This is smaller than required for most scientific purposes. As a result the raw-data rate of such an instrument is about $100 \mathrm{Mbyte} / \mathrm{s}$ and thus too large to be sent down to ground completely. The problem is solved by combining several of the detector pixels to form respective super-pixels in three scientific measurement modes (Table 1):

1. Limb cloud imager mode (LCI): one LCI pixel is one detector pixel (i.e. no spatial co-adding is performed). The limb cloud imager mode achieves a spatial sampling of $0.5 \mathrm{~km}$ vertical, $4 \mathrm{~km}$ across track and $8 \mathrm{~km}$ along track. The spectral sampling is $10-20 \mathrm{~cm}^{-1}$. The LCI mode is optimized for detailed cloud screening.

2. Dynamics mode (D-mode): the high spatial resolution mode is optimized for atmospheric dynamics and has a spatial sampling of $0.5 \mathrm{~km}$ vertical, $24 \mathrm{~km}$ across track and $50 \mathrm{~km}$ along track. In this mode a moderate spectral resolution of $1.25 \mathrm{~cm}^{-1}$ is achieved.

3. Chemistry mode (C-mode): the high spectral resolution mode attains a spectral resolution of $0.2 \mathrm{~cm}^{-1}$ and is optimized for atmospheric chemistry. The spatial sampling is $2 \mathrm{~km}$ in the vertical, $80 \mathrm{~km}$ across track and $80 \mathrm{~km}$ along track.

The concept of an integrated LCI is realized by transmitting simultaneously to the D-mode and C-mode measurements of the centre part of each interferogram for each individual detector pixel. For one D-mode measurement six interferograms along track are co-added in addition to the co-addition of several detector pixels in order to attain one D-mode super-pixel interferogram; therefore the LCI has a finer along-track sampling than the D-mode. The low spectral resolution of $10-20 \mathrm{~cm}^{-1}$ in the LCI mode is still sufficient to identify the presence of clouds and to infer cloud parameters such as cloud extinction, cloud extent, and potentially ice water content and information on the effective radius of the particles. Furthermore, for studying the spatial structures of the clouds an onboard cloud-identification is intended in order to combine only cloud-free detector pixels to super-pixels used for temperature and trace-species retrievals to enhance the benefit from measurements for studies on tropospheric chemistry and STE processes. An overview of the several scientific topics which would particularly benefit from the new limb imaging technique is given by Riese et al. (2005). Two of these topics are examined more closely in this issue.

In the present paper, we demonstrate that very high resolution cloud screening allows (1) to generate unprecedented climatologies of cloud distribution and cloud properties and (2) a largely increase in the number of profiles penetrating the UTLS. In a companion paper Preusse et al. (2009) show that IR limb imaging has the great potential for measuring direction-resolved gravity wave momentum flux.

For the cloud analysis we will simulate limb-sounding measurements throughout a 3-D cloud distribution reflecting our current state of knowledge. We use two different methods to estimate these cloud distributions. The first method derives the cloud top heights from a global composite of IR brightness temperatures (Janowiak et al., 2001). The limitation of this method is that the nadir viewing instruments are insensitive to optically thin clouds which the limb sounder can measure quite effectively due to the long limb path (Spang et al., 2002; Kerridge et al., 2004). The second method calculates the cloud distribution from the ice water content (IWC) and liquid water content (LWC) of the Consortium for Small-scale Modeling-Europe (COSMO$\mathrm{EU})$, which is the operational mesoscale model of the German Meteorological Service (DWD) (Steppeler et al., 2003). Since there are as yet no adequate measuring methods, these data are not well validated for the finer scales of thin clouds 
we are particularly interested in. Only by combining the two methods we can estimate the benefits of the LCI more realistically. Still, in case of thin clouds the uncertainties might be even larger than indicated by the differences between the results of the two methods.

The paper is organized as follows. Section 2 describes the analysis technique. In Sect. 3 we analyse the BT data in terms of the gain in information from the very high spatial resolution of the LCI. Section 4 compares the simulated and modeled cloud distributions and the increase in information determined from both analysed data sets. Section 5 summarizes the results.

\section{Analysis technique}

\subsection{Cloud topography model}

Our simulations are based on 3-D cloud data derived from measurements or atmospheric modelling. In order to demonstrate the benefit of the very highly spatial resolved LCI measurement mode of an infrared limb imager (ILI) the spatial resolution of these cloud data must be comparable with or finer than the resolution achieved by the LCI. We were therefore unable to rely on previous limb sounding measurements or global-model results.

The two methods used in this study provide cloud distributions of a sufficiently fine scale. The first method has been employed since the first weather satellite, which was put into operation in 1960, had provided brightness temperature data with a good availability (Sherwood et al., 2004). Here we use a 2-D composite of IR brightness temperatures measured with the operational geostationary weather satellites. The composite offers a spatial resolution of $\sim 4 \mathrm{~km}$ and a temporal resolution of at least $1 \mathrm{~h}$ as well as a coverage of nearly the entire globe $\left(\sim 60^{\circ} \mathrm{N}-60^{\circ} \mathrm{S}\right)$ (Janowiak et al., 2001). The brightness temperatures are assumed to be the temperatures of the cloud tops which are matched to local ECMWF temperature profiles to obtain the cloud top height. The result is a nearly global map of cloud top heights. Because only the cloud top heights are available and not the complete 3D cloud structure, we assume that the cloud extends down to the ground. The spatial resolution of the resulting cloud topography is $4 \mathrm{~km}$ horizontally. In the vertical we need to discretize to $0.5 \mathrm{~km}$ steps, since this is the vertical sampling of the LCI mode. This sampling is finer than the accuracy of the inferred altitudes. However, since we only need generally realistic cloud topography, this oversampling is justified for the purpose of this paper. The example shown in Fig. 1a is for one specific longitude. In order to obtain full horizontal coverage the process is repeated for all longitudes of the map. The data from October 2005 to October 2006 were processed for this method. We calculate the cloud distribution for every fourth day and the times 00:00, 06:00, 12:00 and 18:00 UTC. (a)

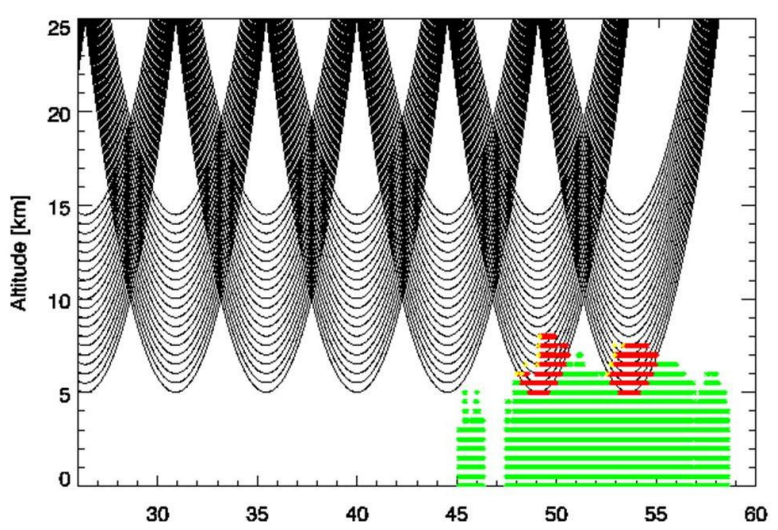

(b)

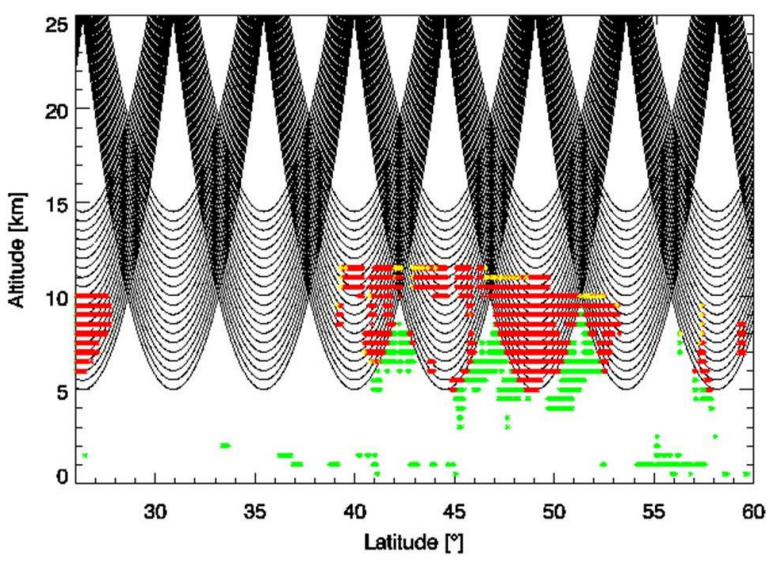

Fig. 1. Extract of the cloud topography models (green symbols give cloudy bins) with simulated LOS (parabola) for 4 November 2005 at 12:00 UTC at $\sim 13^{\circ} \mathrm{E}$. (a) Cloud data from the composite of IR brightness temperatures, (b) cloud data from the COSMO-EU model. The red symbols are intersections of an LOS element and cloudy bins, the yellow symbols show the first cloudy LOS element. For better representation of the limb scan sequences a coarse along track sampling of $\sim 500 \mathrm{~km}$ is chosen.

In the following, the cloud topographies based on IR brightness temperatures are called BT data.

The second method uses the liquid water content (LWC) and the ice water content (IWC) forecast with the COSMO$\mathrm{EU}$, an operational mesoscale numerical weather prediction (NWP) model, which covers the whole of Europe (coordinates left bottom: $9.14^{\circ} \mathrm{W}, 27.7^{\circ} \mathrm{N}$; right bottom: $34.67^{\circ} \mathrm{E}$, $26.12^{\circ} \mathrm{N}$; left top: $34.24^{\circ} \mathrm{W}, 65.58^{\circ} \mathrm{N}$; right top: $63.47^{\circ} \mathrm{E}$, $62.4^{\circ} \mathrm{N}$ ) (Steppeler et al., 2003). Unlike the first method, COSMO-EU provides the 3-D structure of the clouds in a way which is sufficient for estimating the cloud fraction along a LOS. The horizontal spatial resolution is $\sim 7 \mathrm{~km}$ and the model has 41 vertical levels with a resolution of $<0.5 \mathrm{~km}$ near the ground increasing to $>2 \mathrm{~km}$ at the highest level at about $23 \mathrm{~km}$ altitude. For the purpose of comparing two cloud topography models the vertical sampling is interpolated to a $0.5 \mathrm{~km}$ grid. The example shown in Fig. $1 \mathrm{~b}$ is 
for one specific longitude for the model data. The data of November, December 2005 and July, August 2006 were investigated for this method. If available, the cloud distribution is calculated for 00:00, 06:00, 12:00 and 18:00 UTC data. In the following, the cloud topographies calculated in this way are called COSMO-EU data.

\subsection{Simulation of limb sounding measurements}

Limb sounding measurements are simulated in an altitude versus horizontal distance cross section (Fig. 1). In an altitude-horizontal distance geophysical coordinate system the line of sight (LOS) can be approximated near the tangent points as a parabola (Preusse et al., 2002). For a polar orbit we assumed a LOS straight from south to north, which simplifies the calculations. In addition, we neglect refraction. For a real retrieval we would need to take these effects into account exactly, but they can be approximated for our statistical analyses. The tangent heights are located between $5 \mathrm{~km}$ and $19 \mathrm{~km}$. Each LOS extends $\pm 500 \mathrm{~km}$ relative to the tangent point (TP). The TP is the closest point to the Earth's surface.

The LOS is interpolated onto the grid of the cloud topography model. Then the intersections between the LOS and the cloud grid points are determined (Fig. 1). If an LOS intersects a cloud, we usually find more than one intersection. The grid is chosen to have the same resolution as the LCI ( $4 \mathrm{~km}$ across track, $0.5 \mathrm{~km}$ vertical and $8 \mathrm{~km}$ along track). For both the BT data and the COSMO-EU LWC data the LOS is considered to be "cloudy" if there is at least one intersection. In addition, for the COSMO-EU IWC data (where minimum $/$ maximum IWC values of around $10^{-11} \mathrm{~kg} / \mathrm{kg}$ respectively can be found) the LOS is considered to be "cloudy" if the integrated IWC along the entire LOS path exceeds at least $5 \times 10^{-2} \mathrm{~g} \mathrm{~m}^{-2}$. This threshold is based on radiative transfer calculations for large database of modelled cloud spectra with the Karlsruhe Optimized and Precise Radiative transfer Algorithm (KOPRA) radiative transport model including single scattering effects (Höpfner, 2004) together with measurements of Michelson Interferometer for Passive Atmospheric Sounding (MIPAS) instrument (Fischer et al., 2008). Results for the ESA study on MIPAS cloud parameter retrieval (Spang et al., 2008) can be interpreted, that a limb ice water path of $5 \times 10^{-2} \mathrm{~g} / \mathrm{m}^{2}$ could be detectable in the IR spectra under certain conditions (e.g. in the tropopause region with its current extremely low background aerosol load). This threshold results in an effective IWC of $10^{-6}$ for a $50 \mathrm{~km}$ limb cloud path. Therefore only those ice-water path values are included which show clouds with sufficient optical thickness.

So far we have considered the LOS to be an infinitesimally thin line. In reality the LOS projects an area, the so-called field of view (FOV), on the measurement object (atmosphere), i.e. instead of an infinitesimally thin parabola the measurement volume is taken from an arch-shaped three- dimensional volume. In addition, the motion of the satellite shifts this volume along the satellite track while an interferogram is being taken, which also contributes to the shape of the 3-D measurement volume. While one interferogram in the D-mode is being measured, for example, the satellite moves $8 \mathrm{~km}$ and therefore the signal is integrated over this distance. Therefore the motion of the satellite as well as the FOV has taken account for the simulation. The method is described in following paragraph.

We now compare cloud characteristics for the D-mode and the $\mathrm{C}$-mode against the simulated measurements of the LCI, using LCI as a standard. In order to downscale the very high spatial resolution of the LCI to the lower resolution of the Dmode and the $\mathrm{C}$-mode, the corresponding number of observations are combined in all three dimensions. The combination of corresponding number of observations in the vertical and the across-track direction accounts for the various FOVs. The combination of observations along track includes the shift of the volume due to of the motion of the satellite in the simulation. The resulting measurement volume is the new observation of the respective lower resolution measurement mode. The position of the new tangent point is in all three dimensions the central observation of the combined tangent points. LCI mode measurements are associated with a single pixel. In analogy, we call the integrated measurements in the Dmode and C-mode super-pixel measurements. It should be kept in mind that this includes temporal as well as spatial coadding. For the analyses, in a first step approach we assume that a super-pixel is cloudy if it contains one cloudy pixel.

\section{Results of BT data}

\subsection{Cloud occurrence distribution}

In order to quantify the increase in information of the high spatial resolution provided by the LCI in comparison to the D-mode and C-mode, the cloud occurrence for the BT data was determined. To this end latitude bins of $2.5^{\circ}$ were created and all observations and all cloudy observations were counted and the ratio between the two calculated. The result is the cloud occurrence $f_{c}(i)$ :

$f_{c}(i)=\frac{N_{c}(i)}{N(i)}$

$N(i)$ is the total number of observations concerning the defined latitude bins over all longitudes at height $z(i)$ with $i=1 \ldots n$ from the lowest to the highest level. $N_{c}(i)$ is the total number of all cloudy observations at level $i$.

Figure 2 shows the zonal averaged cloud occurrence for October 2005 deduced from the BT data for the three modes of the ILI. The general distribution of the cloud occurrence is latitude-dependent. The strongest cloudiness of 59 to $80 \%$ occurs in the tropics up to $9 \mathrm{~km}$; at midlatitudes the cloud fraction decreases. Maximum cloud top heights in the tropics reach up to $15 \mathrm{~km}$; at midlatitudes maximum cloud top 

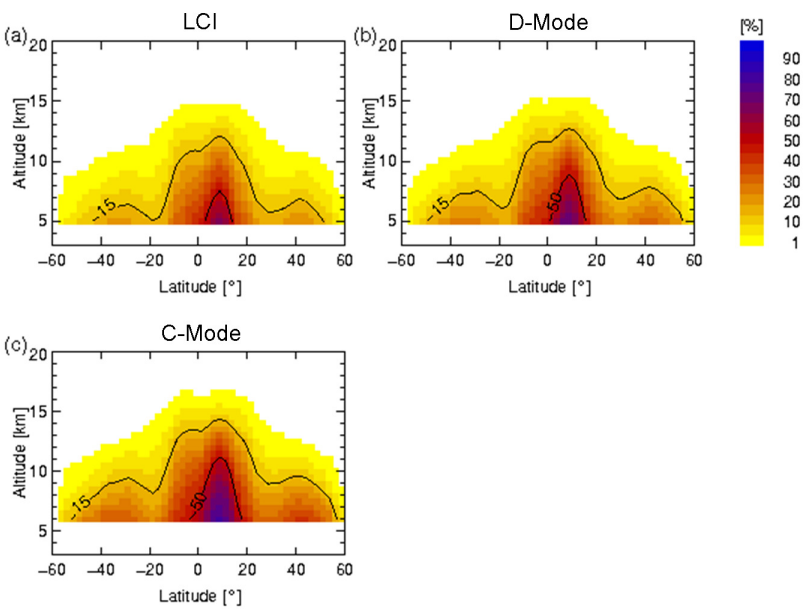

Fig. 2. Zonal mean of the fraction of the cloud occurrence for LCI, D-mode and C-mode averaged for all available BT data of October 2005.

heights are around $10 \mathrm{~km}$. The cloud top height follows the tropopause, which is higher in the tropics and decreases at higher latitudes indicating that the cloud structure simulations for different spatial resolutions of the ILI based on BT method are in general realistic. However, we assume that the cloud amount represented by the BT method is underestimated. According to Kerridge et al. (2004) the optical thin clouds, which are in particular subvisible cirrus, are not detected by the nadir sounding geostationary weather satellites because the emissions resulting from their low optical depth relative to the strong emissions from the ground and altitudes below the level of interest do not induce a clear signal at the sensor. In order to validate the simulated distributions of the opaque clouds in limb direction we compare them with the zonal averages of accumulative opaque cloud distributions measured with the limb sounding Stratospheric Aerosol and Gas Experiment (SAGE) 1997/98 and DJFMA climatology (1985-1991) (Fig. 3) (Wang et al., 2003). Simulated and measured cloud distributions are similar in general, but the cloud occurrences simulated with the LCI for winter 2005/06 show an underestimation of about $20 \%$ with respect to the cloud occurrences measured with SAGE. The underestimation of both optical thin clouds as well as opaque clouds will result in an underestimation of the benefit by the LCI. We use the BT data because it is the only data set with nearly global coverage and a sufficiently high spatial resolution. Although simulated cloud distributions based on model data may better reproduce measured cloud occurrences (model data also contain optical thin clouds) the spatial resolution of the data is not sufficient $(\sim 25 \mathrm{~km}$ in ECMWF is the highest resolution available for the global model) or they do not allow global coverage. This problem is discussed in detail in Sect. 4.

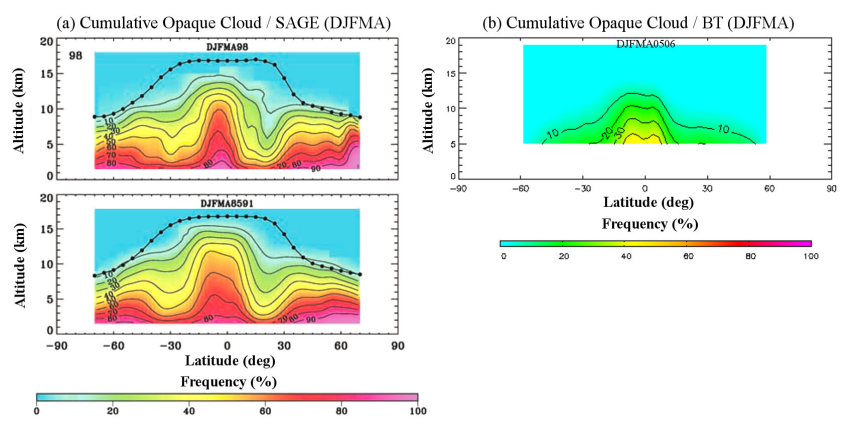

Fig. 3. (a) Zonal mean cumulative opaque cloud distribution for the 1997/98 El Niño 1997/98 and the DJFMA climatology (1985-1991) (Wang et al., 2003), (b) zonal mean cumulative opaque cloud distribution for December 2005 to April 2006 from BT method, measured with simulated LCI $\left(4 \times 0.5 \times 8 \mathrm{~km}^{3}\right)$.

\subsection{Gain in information}

Regarding the increase in information, the changes between the three different spatial resolutions are examined. Figure 4 shows the zonal averaged frequency of the cloud occurrence from 5 to $15 \mathrm{~km}$. The increase of the cloud occurrence rate is about $5 \%$ cloud fraction from LCI to D-mode both in the tropics and the midlatitudes and is about $15 \%$ cloud fraction from LCI to C-mode. In addition, the comparison of LCI and $\mathrm{C}$-mode shows that a reduced vertical resolution simulates higher cloud top heights.

This is also demonstrated in Fig. 5, which shows the differences $D$ of the cloud occurrence between D-mode and C-mode $f_{c, D} / \mathrm{C}$-mode, respectively, and LCI $f_{c, 0 \mathrm{LCI}}$ for four months as representatives of the different seasons:

$D=f_{c, \mathrm{D} / \mathrm{C}-\text { Mode }}-f_{c, \mathrm{LCI}}$

Panels (a) and (e) of Fig. 5 show the differences $D$ for October 2005. Generally, the largest effect of the resolution can be seen within the tropics and to some extent in the northern midlatitudes. According to Fig. 4, these are the regions with the highest cloud amount. The largest difference for the Dmode is $10 \%$ cloud occurrence rate, whereas for the $\mathrm{C}$-mode it is twice as high due to the further reduction of the spatial resolution. Due to the lower vertical resolution of the Cmode, in contrast to LCI and D-mode larger differences are caused at higher altitudes. Consequently, measurement with a lower spatial resolution overestimates the fraction of clouds and the cloud top heights because the smaller gaps in cloud fields are not resolved. With an instrument measuring only at $\mathrm{C}$-mode resolution a great many profiles were not usable for trace gas retrieval. This problem is discussed in more detail in Sect. 4.3. The more finely structured distribution produced by the LCI shows that the detailed cloud detection allows a distinction to be made between cloudy and non-cloudy observations. Improved tropospheric coverage by these modes can be reached by combining only the non-cloudy pixels into 

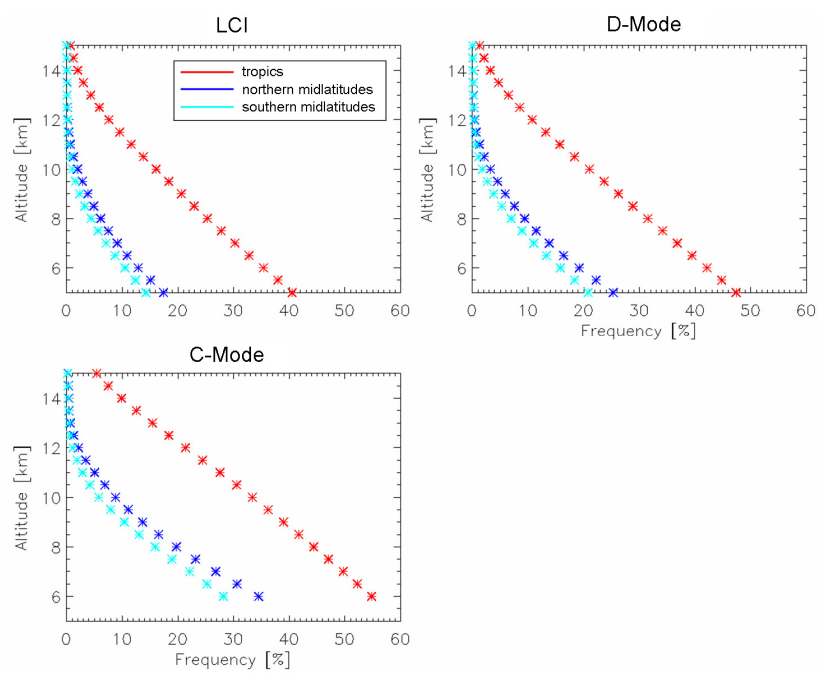

Fig. 4. Zonal averaged frequency of the BT cloud occurrence from 5 to $15 \mathrm{~km}$ for tropics $\left(23.75^{\circ} \mathrm{N}-23.75^{\circ} \mathrm{S}\right)$, northern $\left(32.25^{\circ} \mathrm{N}-\right.$ $\left.58.75^{\circ} \mathrm{N}\right)$ and southern $\left(32.25^{\circ} \mathrm{S}-58.75^{\circ} \mathrm{S}\right)$ midlatitudes, for October 2005 (averaged over all available data).

the super-pixels of the more coarsely resolved measurement modes (in particular for C- and D-mode).

\subsection{Annual variabilities}

Figure 5 shows for all seasons the differences of the cloud occurrence between the D-mode and C-mode, respectively, and the LCI. The general distribution of the differences is, as described in the previous section, strongest in the tropics and to some extent in the northern midlatitudes. The great differences in the tropics over all the seasons represent the regions with the highest cloud amount. According to ISCCP (2008), the highest cloud amount is in the area of the inner tropical convergence zone (ITCZ). The ITCZ located in the tropics is shifted towards the respective summer hemisphere. The differences of the cloud amount in Fig. 5 indicate these shifts. The ITCZ as well as the greatest differences in January are located more southerly and in July more northerly with respect to the equator. The position of the ITCZ in October and April and consequently the greatest differences in these months occur for an intermediate state of the ITCZ. Further aspects are the greater differences over all latitudes of the cloud amount in July than in January and the greater differences over all seasons at northern midlatitudes compared to the southern midlatitudes. This suggests a possible stronger or fragmentary cloudiness in July and in the northern midlatitudes.

With respect to the annual variability in 2005/06 the largest differences and thus the highest efficiency of the LCI are located in the strongest cloudiness region in the tropics which moves with the ITCZ. The greater difference in the northern midlatitudes in contrast to the southern midlatitudes is independent of season.
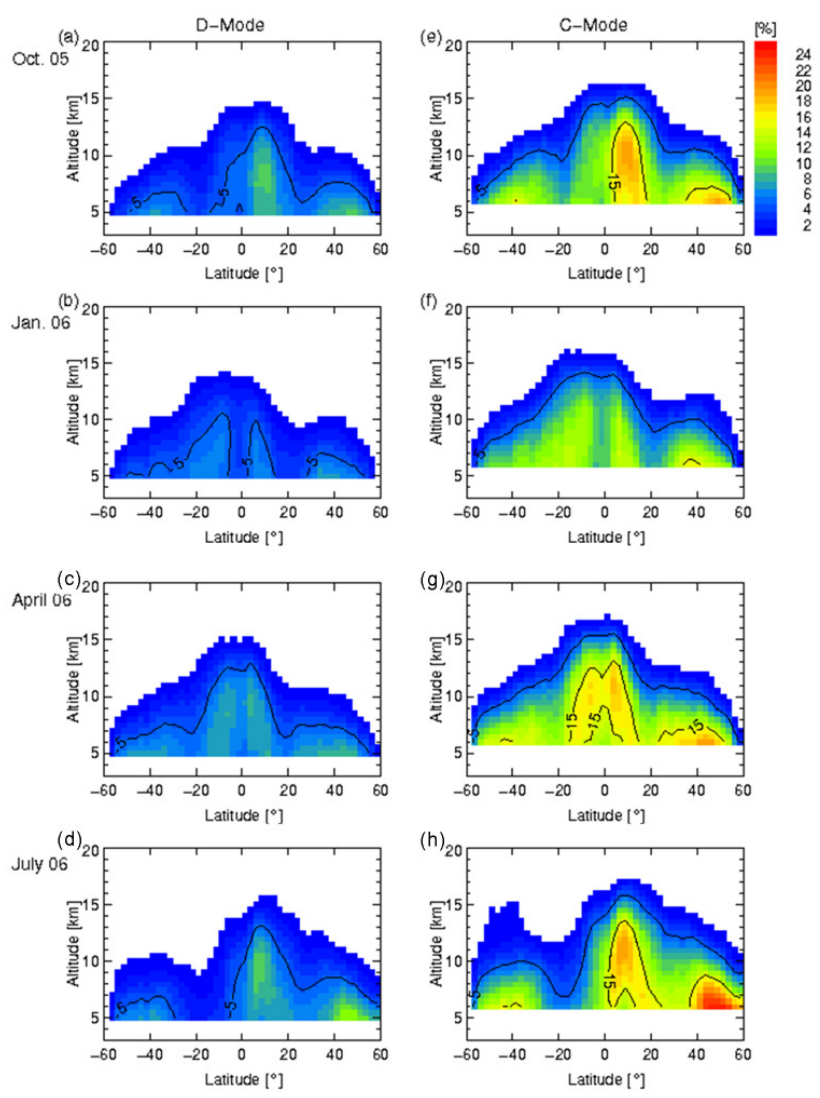

Fig. 5. Difference of the BT cloud occurrence between LCI and (ad) D-mode, respectively, (e-h) C-mode for October 2005, January 2006, May 2006, July 2006 (month mean).

\subsection{Quantification of effects of the three dimensions}

The cloud coverage depends differently on the resolution in each of the three dimensions defined by the measurement geometry. These dimensions are the vertical and across-track resolution governed by the measurement geometry and the along-track resolution governed by the integration of the signal as the satellite moves during the measurement. In order to optimize the instrument concept it is important to quantify how strongly the cloud content increases when the spatial resolution is reduced in each of these three dimensions. Based on this information, the spatial sampling of the instrument can be optimized to accommodate these needs. One question in particular is whether the effort for high spatial resolution in the respective directions is well balanced or whether the resolution has been increased in one direction at the expense of neglecting a more important direction? For instance, the direction of the lowest sampling is currently along-track, since the concept of the integrated LCI only permits for one cloud identification per interferogram. In the D-mode this corresponds to every $50 \mathrm{~km}$. In the C-mode, however, in a worst case scenario only one LCI interferogram every $80 \mathrm{~km}$ is downlinked. It must be asked whether this is sufficient. 

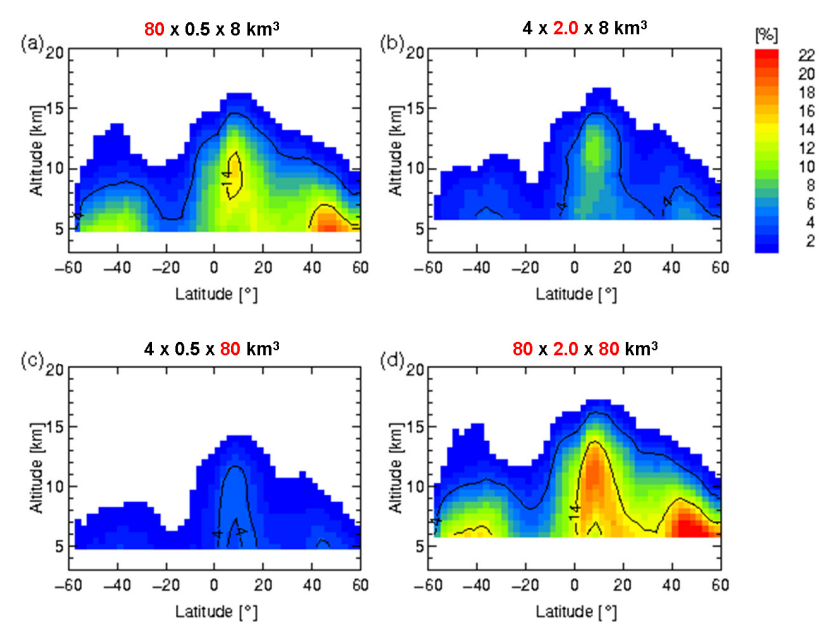

Fig. 6. Differences of percentage of the BT cloud occurrence between LCI and a simulation of limb sounding measurements where the spatial resolution (a) horizontal across-track, (b) vertical, (c) horizontal along-track, and (d) in all three directions is changed for July 2006. The spatial resolution is indicated as follows: horizontal across-track $\mathrm{x}$ vertical $\mathrm{x}$ horizontal along-track. Numbers highlighted in red show the modification of the spatial resolution.

Figure 6 shows the difference $D$ of the cloud occurrence between LCI and the simulated limb sounding measurements where the spatial resolution is reduced in one direction (Fig. 6a-c) and where the spatial resolution is reduced in all three directions (Fig. 6d). The differences in the change of the along-track resolution are smallest (Fig. 6c). The maximum change of $6 \%$ cloud occurrence rate is located in the tropics. Most of the other areas show only a difference of $2 \%$. The small differences result from the limb-sounding geometry. Over a long distance, the LOS passes low altitudes where the cloud amount is high. For example, between a cloud top height at $18 \mathrm{~km}$ and a tangent point at $10 \mathrm{~km}$ the LOS passes a distance of $\sim 320 \mathrm{~km}$ and another $320 \mathrm{~km}$ until $18 \mathrm{~km}$ is reached again. Over this entire distance of $640 \mathrm{~km}$ the LOS reacts sensitively to clouds. Whether the LCI measurement is sampled every $8 \mathrm{~km}$ or every $80 \mathrm{~km}$ therefore has little impact. In contrast to this, the differences of the horizontal resolution across track are the largest (Fig. 6a). In the tropics and the midlatitudes of the Northern Hemisphere the difference is up to $16 \%$ cloud occurrence rate, and in the midlatitudes of the Southern Hemisphere up to $11 \%$. This is caused by the greater probability of hitting an additional, so far undetected cloud when the FOV is enlarged in this direction. The change of the vertical resolution moderately affects the fraction of the cloudy LOS (Fig. 6b). The maximum difference is between $11 \%$ cloud occurrence rate in the tropics and $6 \%$ in the midlatitudes. Figure $6 \mathrm{~d}$ shows the total change when the spatial resolution is reduced in all directions to $\mathrm{C}$-mode sampling. The distribution looks similar to that in Fig. 6 a but the overall difference is a few percent higher. The maximum difference is $22 \%$ at $10-12 \mathrm{~km}$ in the tropics.
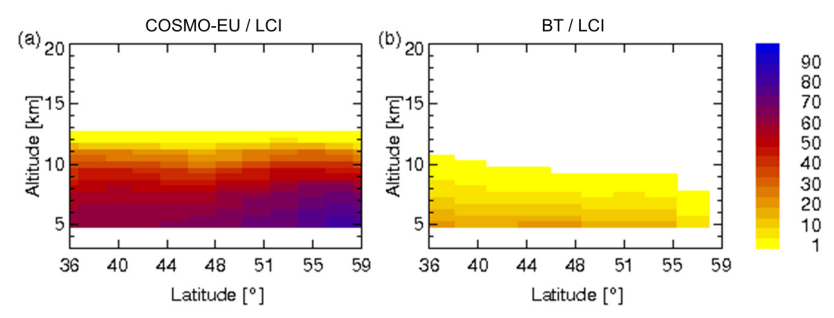

Fig. 7. Cloud occurrence observed with simulated LCI for BT and COSMO-EU data. Mean of 30 days in November and December 2005.

The compatible numbers for vertical and across-track resolution demonstrate that the spatial oversampling by LCI pixels has been well chosen and is balanced for these two directions. The low sampling rate along track is technologydriven. However, the study confirms that this dimension is the least important one and that the aim of the LCI to increase the tropospheric coverage in terms of retrieved temperatures and trace gas distributions is not affected.

\section{Comparison of the BT and COSMO-EU cloud topog- raphy}

\subsection{Comparison of the cloud distribution}

The BT cloud data and the COSMO-EU cloud data are compared with respect to the cloud occurrence rate and the horizontal cloud extent. Figure 7 shows the cloud occurrence observed with the simulated LCI for BT and COSMO-EU data. Since the COSMO-EU data are only available over Europe the same region is extracted for the BT data. The latitude range from $30^{\circ} \mathrm{N}$ to $65^{\circ} \mathrm{N}$ is divided into bins of $2.5^{\circ}$ as described in Sect. 3. It is obvious that the cloud occurrence and the cloud top heights of the COSMO-EU data are higher over all the latitudes. When comparing the cloud amount of the two data sets by means of the cloud occurrence shown in Fig. 7, it should be noted that the strong differences of the cloud occurrence in the lower measurement range of the atmosphere result partly from the LOS geometry. We attribute the "cloudy" measurement to the TP, but the cloud may also be located at another position along the LOS. The LOS passes through the atmosphere from top to down and therefore the path length through the cloud field becomes longer with descending tangent height (Fig. 1). Therefore, the cloud detection rate and the simulated limb sounding cloud occurrence rate accumulate downwards. Both data sets show this effect, but for the COSMO-EU data it is more effective because of the higher simulated cloud amount. Nevertheless, the cloud occurrence calculated with the COSMOEU data is significantly higher and more realistic than that calculated with the BT data, which can be seen by a comparison with SAGE measurements (Fig. 3). 

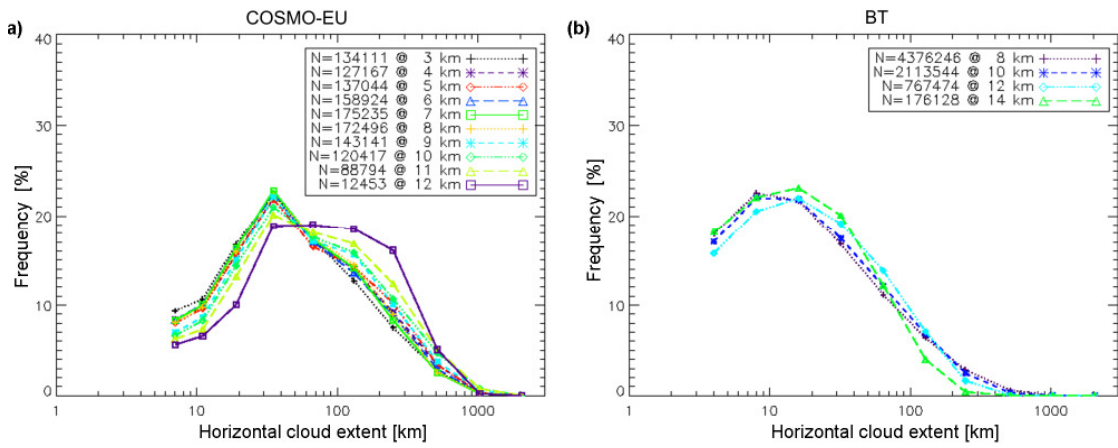

Fig. 8. Frequency distribution of the cloud extent from south to north for BT and COSMO-EU data, averaged over November and December 2005. The horizontal dimension of the cloudy bins, which are directly abutting to each other, is measured for every height. The minimum extent is given by the spatial resolution. $N$ is the amount of cloudy bins at the given height.

The horizontal cloud extent in the south-north direction for both data sets is shown in Fig. 8. The distribution for the BT data peaks at about $10-20 \mathrm{~km}$, but also clouds with an extent of $4 \mathrm{~km}$ have a high relative occurrence rate. For the COSMO-EU data the maximum occurrence is found at about $30 \mathrm{~km}$, but the occurrence rate decreases rapidly at smaller cloud extents and the smallest cloud structures have an extent of $7 \mathrm{~km}$ due to the horizontal resolution of the COSMO-EU.

The big differences in the two cloud data sets in Fig. 7 result from the differences in the applied cloud data of the two methods. The method for deriving the BT cloud data seems to underestimate the occurrences of high altitude clouds compared to the COSMO-EU results, which are restricted to a mid-latitude region. The method is most sensitive and optimised to optically thick clouds (Sect. 3.1). Optically thin cloud in the nadir direction will result in a significant underestimation of the real cloud top height due penetrating radiation by lower altitudes and surface emissions through the cloud. In consequence the BT clouds distribution will underestimate in a certain extent the cloud occurrence with respect to height (Kerridge et al., 2004). However, the cloud extent, especially the small cloud fields, is reproduced more realistically. In contrast to this, the COSMO-EU data seem to show a more realistic cloud amount because of the representation of the high altitude and optically thin clouds. On the other hand, the cloud occurrence simulated from the COSMO-EU data compares better to the SAGE data, presumably due to the representation of the optically thin clouds. But due to the lower spatial resolution of the COSMO-EU data $(7 \mathrm{~km}$ grid size) the cloud cover is too homogeneous and too many cloudy pixels are simulated for the high spatial resolution of the LCI.

We conclude from this analysis that neither data set reproduces the cloud distribution in its entirety. However, the limitations of the two data sets concern two different aspects of the cloud information. The combination of the results from both data sets can give the best picture of the increase in information due to the high spatial resolution of the LCI.

\subsection{Comparison with respect to the measurement modes}

The differences $D$ of the cloud occurrence between D-mode and C-mode, respectively, and LCI for the COSMO-EU data and the BT data are shown in Fig. 9 to quantify the differences between the two data sets. The general distribution for both data sets is similar but the COSMO-EU differences reach higher altitudes (D-mode: $12 \mathrm{~km}, \mathrm{C}$-mode: between 13 and $14 \mathrm{~km}$ ) than the BT differences (D-mode: between 8 and $10 \mathrm{~km}, \mathrm{C}$-mode: between 10 and $12 \mathrm{~km}$ ) and the difference values are higher - in general above $\sim 8 \mathrm{~km}$. This indicates that through the underestimation of the thin clouds in the BT data the gain in information at higher altitudes is underestimated. At lower altitudes, the BT data show the maximum difference in cloud occurrence (D-mode: $11 \%, \mathrm{C}$ mode: $17 \%$ ).

The COSMO-EU data do not reach these maximum values because they do not represent the small cloud fields realistically, as discussed in the last section. If the spatial extent of the clouds is significantly larger than the spatial resolution of the LCI then its benefit will be limited, because negligibly more clouds will be resolved by the LCI than by the D-mode and $\mathrm{C}$-mode. In conclusion, the examination of the two data sets shows that the true benefit of the LCI is likely to be larger than that indicated by each of the respective data sets.

\subsection{Cloud coverage with respect to a super-pixel}

So far we have assumed that a super-pixel is cloudy if one LCI pixel is cloudy, which is a simple conservative criterion. For a more detailed analysis, we determined the fraction of "cloudy" LCI-pixels (co-added in space and time). This observation volume cloud coverage (OVCC) is then used to divide the "cloudy" observations into three classes according to the influence of OVCC on the retrieval of temperatures and trace species. This classification is related to a study of 

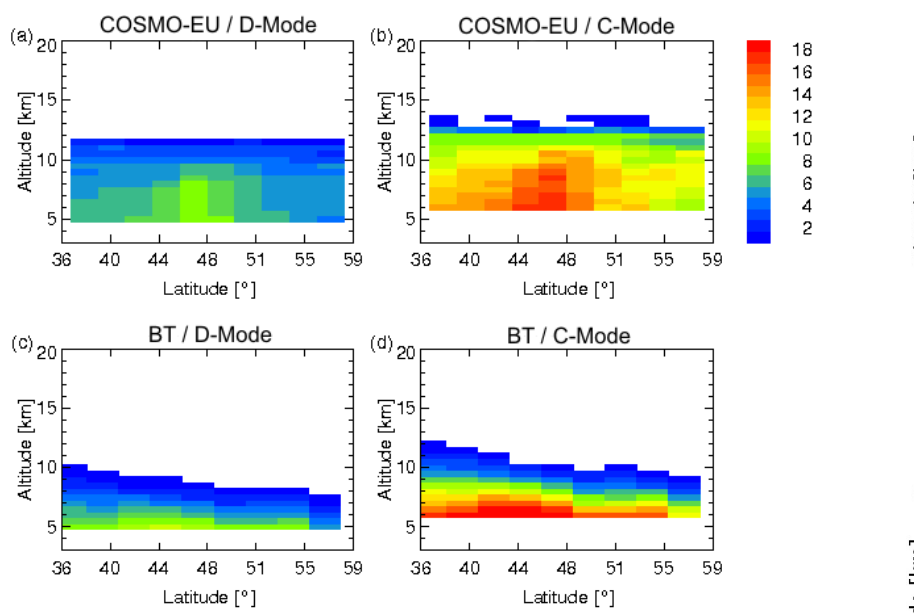

Fig. 9. Comparison of the differences in the cloud occurrence between D-mode and C-mode, respectively, LCI for (a and b) COSMO-EU data and (c and d) BT data, averaged over 30 days in November and December 2005.

the influence of partially cloud filled FOVs on the retrievals by Kerridge et al. (2004):

1. Up to $15 \%$ OVCC: Without knowledge of OVCC the error of the retrieved trace species is substantially increased. If intelligent onboard binning is applied, the measurement can be retrieved at normal (cloud-free conditions) accuracy.

2. Between 15 and 50\% OVCC: retrievals are only possible either by cloud fraction correction during the retrievals or preferentially onboard binning. Even so, retrieval errors are increased.

3. At over $50 \%$ cloud content: the measurement cannot be used for the retrievals.

These classes are only benchmarks and further investigations are necessary to quantify the real cloud effect in spectra measured with a partially cloud-filled FOV.

Based on these three OVCC classes we can statistically assess the benefit of the cloud imager for the retrievals in the two trace gas modes. In the first class the information on cloud fraction will enhance the quality of the retrievals (e.g. by just skipping cloudy pixel in the super-pixel or just by the knowledge that the spectrum has a cloud contamination), for the second class retrievals are only feasible at all if LCI information is taken into account. The third class of profiles is likely not retrievable at all (although in reality this depends on the optical thickness of the cloud layer). However, if the LCI information is used onboard to combine only the cloudfree pixels, several heavily cloudy profiles may be combined to gain information at somewhat reduced spatial resolution.

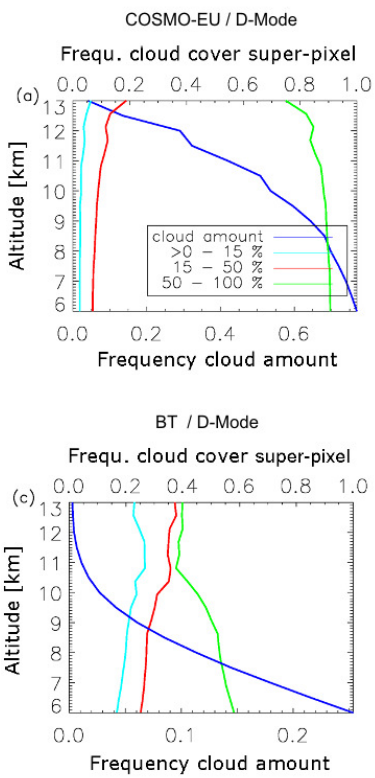

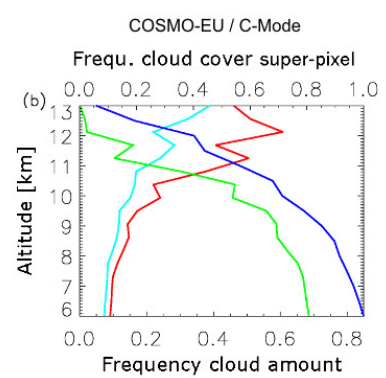

BT /C-Mode

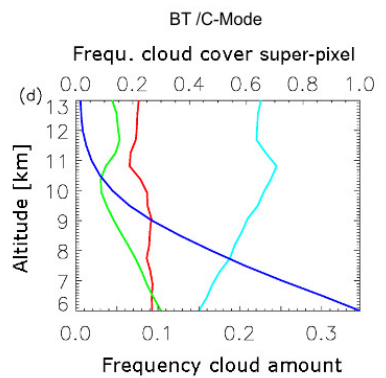

Fig. 10. Cloud occurrence rate (dark-blue curve, lower $\mathrm{x}$-axis) and how this splits into the three classes of cloud coverage inside the respective super-pixels (upper x-axis). Light-blue, green and red curves, respectively, show $0-15 \%, 15-50 \%$ and $50-100 \%$ cloud coverage of the co-added super-pixels (see text for detailed definition). These three classes correspond to profiles (light-blue) for which retrievals are improved in quality by an LCI, (red) for which retrievals can be only performed at all using an LCI, and (green) for which retrievals cannot be performed even with the help of an LCI. Since these are relative distributions with respect to the "cloudy" super-pixels, the three classes always add up to $1(100 \%)$. Shown are results from (upper row) COSMO-EU and (lower row) BT data for simulated (left) D-mode and (right) C-mode measurements for November and December 2005 and the entire region of the COSMO-EU coverage.

For the two trace gas modes and both cloud data sets, Fig. 10 shows for (1) the total cloud occurrence as discussed in the previous sections (dark-blue curves) and (2) how the observations with "cloudy" super-pixels are distributed between the various OVCC classes.

The total cloud occurrence given in Fig. 10 repeats the salient features discussed in Sect. 4. The cloud amount accumulates from high to low altitudes and the BT data underestimate the cloud occurrence rate compared to the COSMO-EU data and to the SAGE measurements, resulting in an underestimation of the benefit of the LCI.

The light-blue, red and green curves show how the "cloudy" super-pixels are distributed between the three OVCC classes. For the COSMO-EU data, the frequency of the super-pixels with low cloud fraction is, especially for the D-mode, very small because the spatial extent of clouds in the COSMO-EU data is, in general, comparable to or larger than the D-mode super-pixels (cf. Fig. 8). Accordingly, only a small fraction of the "cloudy" observation is included in the 
first two classes, for which the retrievals can be greatly improved by the LCI. The BT data, which represent the cloud scales more realistically, show a higher fraction of "cloudy" super-pixels in the first two OVCC classes in the D-mode. For about $20 \%$ of the "cloudy" profiles retrievals can be significantly improved by the LCI cloud information (class 1 , light-blue line) and for about $30 \%$ only the LCI makes the retrievals possible at all (class 2, red line). The largest overall benefit of the LCI is found in panel b) showing C-mode measurements simulated for COSMO-EU data. In the troposphere, up to $85 \%$ of the super-pixels are cloudy. However, more than $20 \%$ of these profiles are found in the first two classes and hence retrievable using LCI information. The LCI therefore almost doubles the coverage by the $\mathrm{C}$-mode in the troposphere.

As in the previous section, the results show that the high spatial sampling of the LCI is extremely valuable for a good coverage of the troposphere. Although for some profiles in OVCC class 2 the signal-to-noise ratio will decrease after selective binning, the combined picture of the cloud characteristics in the corresponding data sets indicates that a substantially higher amount of retrievable profiles will be available for both atmospheric measurement modes.

\section{Summary and conclusion}

The investigation of mesoscale processes requires a new generation of infrared limb sounders imaging the atmosphere with unprecedented spatial resolution. The instrument concept of an infrared limb imager (ILI) presented in this study has three measurement modes, two for the exploration of the atmospheric temperatures and trace gases, and the limb cloud imager (LCI) mode for a detailed cloud screening (cf. Table 1).

The benefit of the LCI for tropospheric temperature and trace gas measurements has been quantified. Since no cloud distributions are available in the required spatial resolution, our investigations are based on two complementary data sets. Cloud topographies deduced from cloud brightness temperatures (BT data) measured by nadir viewing satellites have a high horizontal resolution of $4 \times 4 \mathrm{~km}^{2}$, but underestimate, in particular, optically thin clouds in the upper troposphere. Cloud topographies calculated from the Consortium for Small-scale Modeling-Europe (COSMO-EU) data include optical thin clouds, but due to a $7 \mathrm{~km}$ grid resolution the horizontal extent of the individual clouds is overestimated and only very few clouds are smaller than $20 \mathrm{~km}$. As a result, both data sets tend to underestimate the potential benefit of the LCI data.

First, we investigated how the cloud occurrence rate (including partially cloud-filled measurement volumes) increases when single-pixel observations are co-added to super-pixels, which provide the signal-to-noise ratio required for retrievals. The differences between the LCI and D-mode and C-mode, respectively, are largest in regions of high cloud occurrence. Typical differences in the tropical troposphere for the C-mode are about $15 \%$ cloud occurrence rate. In the northern midlatitudes, differences of up to $25 \%$ cloud occurrence rate are found.

Separately investigating the differences for the three spatial dimensions, vertical, across track and along track, shows roughly equal increases in cloud occurrence rate for vertical and across-track co-addition. This indicates that we have attached appropriate relative significance to increase the resolution in the respective dimension. Due to the limb sounding geometry the influence of the along-track resolution is low. An increase from $8 \mathrm{~km}$ (LCI) to $80 \mathrm{~km}$ (C-mode) sampling distance results in differences of less than $2 \%$ cloud occurrence rate. Since it is technology-driven, the along-track resolution of the LCI in the C-mode could also be as low as $80 \mathrm{~km}$, which, however, does not pose a problem for the aims of the LCI as this study shows.

Finally, the amount of profiles which can be greatly improved or indeed retrieved at all by including LCI information was quantified by dividing the cloud cover of individual super-pixels from the two trace-gas modes (D-mode and Cmode) into three classes according to their influence on the retrievals. According to COSMO-EU data, the LCI might double the amount of retrievable profiles from $\mathrm{C}$-mode observations in the midlatitudes midtroposphere $(6-10 \mathrm{~km}$ altitude), which is a substantial improvement for future IR limb sounding of the troposphere.

Acknowledgements. The Global-merged IR Brightness Temperature Data was provided by the NASA Goddard Earth Sciences Distributed Active Archive Center (GES DAAC) and can be downloaded from their website at http://disc.sci.gsfc.nasa.gov. The data of the Consortium for Small-scale Modeling-Europe (COSMO-EU) was provided by the DWD. We thank D. Schröder (Environmental Meteorological Department, University of Trier) for his help in retrieving and understanding the COSMO-EU data. Thanks are also due to R. Bauer (Forschungszentrum Jülich, ICG I) for programming support.

Edited by: B. Mayer

\section{References}

Bacmeister, J. T., Kuell, V., Offermann, D., Riese, M., and Elkins, J. W.: Intercomparison of satellite and aircraft observations of ozone, CFC-11, and NOy using trajectory mapping, J. Geophys. Res., 104(D13), 16379-16390, 1999.

Canziani, P. O.: Slow and ultraslow equatorial Kelvin waves: The UARS-CLAES view, Q. J. Roy. Meteorol. Soc., 125, 657-676, 1999.

Ern, M., Preusse, P., Krebsbach, M., Mlynczak, M. G., and Russell III, J. M.: Equatorial wave analysis from SABER and ECMWF temperatures, Atmos. Chem. Phys., 8, 845-869, 2008, http://www.atmos-chem-phys.net/8/845/2008/.

European Space Agency: PREMIER: Candidate Earth Explorer Core Missions - Reports for Assessment, ESA SP-1313(5), Mis- 
sion Science Division, ESA-ESTEC, Noordwijk, The Netherlands, ISSN 0379-6566, 121 pp., 2008.

Ewen, G. B. L., Grainger, R. G., Lambert, A., and Baran, A. J.: Infrared radiative transfer modelling in a $3 \mathrm{D}$ scattering cloudy atmosphere: Application to limb sounding measurements of cirrus, J. Quant. Spectrosc. Ra., 96, 45-74, 2005.

Fetzer, E. J. and Gille, J. C.: Gravity wave variance in LIMS temperatures. Part I: Variability and comparison with background winds, J. Atmos. Sci., 51, 2461-2483, 1994.

Fischer, H., Birk, M., Blom, C., Carli, B., Carlotti, M., von Clarmann, T., Delbouille, L., Dudhia, A., Ehhalt, D., Endemann, M., Flaud, J. M., Gessner, R., Kleinert, A., Koopman, R., Langen, J., López-Puertas, M., Mosner, P., Nett, H., Oelhaf, H., Perron, G., Remedios, J., Ridolfi, M., Stiller, G., and Zander, R.: MIPAS: an instrument for atmospheric and climate research, Atmos. Chem. Phys., 8, 2151-2188, 2008,

http://www.atmos-chem-phys.net/8/2151/2008/.

Friedl-Vallon, F., Riese, M., Maucher, G., Lengel, A., Hase, F., Preusse, P., and Spang, R.: Instrument concept and preliminary perfermance analysis of GLORIA, Advances in Space Research, 37(12), 2287-2291, doi:10.1016/j.asr.2005.07.075, 2005.

Höpfner, M.: Study on the impact of polar stratospheric clouds on high resolution mid-IR limb emission spectra, J. Quant. Spectrosc. Ra., 83(1), 93-107, 2004.

Höpfner, M., Larsen, N., Spang, R., Luo, B. P., Ma, J., Svendsen, S. H., Eckermann, S. D., Knudsen, B., Massoli, P., Cairo, F., Stiller, G., v. Clarmann, T., and Fischer, H.: MIPAS detects Antarctic stratospheric belt of NAT PSCs caused by mountain waves, Atmos. Chem. Phys., 6, 1221-1230, 2006,

http://www.atmos-chem-phys.net/6/1221/2006/.

ISCCP: Cloud Analysis - Part 3: Seasonal Variations of Cloud and Surface Properties, online available at: http://isccp.giss.nasa.gov/ climanal3.html, last access: 22 May 2008.

Janowiak, J. E., Joyce, R. J., and Yarosh, Y.: A Real-Time Global Half-Hourly Pixel-Resolution Infrared Dataset and Its Applications, B. Am. Meteor. Soc., 82, 205-218, 2001.

Kerridge, B., Siddans, R., Reburn, J., et al.: Consideration of mission studying chemistry of the UTLS, Final Report, section 13: Generation of a cloud limb opacity climatology, ESTEC Contract No 15457/01/NL/MM, 113-143, 2004.

Konopka, P., Spang, R., Gunther, G., Muller, R., McKenna, D. S., Offermann, D., and Riese, M.: How homogeneous and isotropic is stratospheric mixing? Comparison of CRISTA-1 observations with transport studies based on the Chemical Lagrangian Model of the Stratosphere (CLaMS), Q. J. Roy. Meteorol. Soc., 131, 565-579, 2005.

Kuell, V., Riese, M., Tie, X., Wiemert, T., Eidmann, G., Offermann, D., and Brasseur, G. P.: $\mathrm{NO}_{\mathrm{y}}$ partitioning and aerosol influences in the stratosphere, J. Geophys. Res., 107(D23), 8183, doi:10.1029/2001JD001246, 2002.

McIntyre, M. E. and Palmer, T. N.: The surf zone in the stratosphere, J. Atmos. Terr. Phys., 46, 825-849, 1984.

Offermann, D., Grossmann, K. U., Barthol, P., Knieling, P., Riese, M., and Trant, R.: The CRyogenic Infrared Spectrometers and Telescopes for the Atmosphere (CRISTA) experiment and middle atmosphere variability, J. Geophys. Res., 104, 16311-16325, 1999.

Offermann, D., Schaeler, B., Riese, M., Langfermann, M., Jarisch, M., Eidmann, G., Schiller, C., Smit, H. G. J., and Read, W. G.:
Water vapor at the tropopause during the CRISTA 2 mission, J. Geophys. Res., 107(D23), 8176, doi:10.1029/2001JD000700, 2002.

Preusse, P., Schroeder, S., Hoffmann, L., Ern, M., Friedl-Vallon, F., Oelhaf, H., Fischer, H., and Riese, M.: New perspectives on gravity wave remote sensing by spaceborne infrared limb imaging, Atmos. Meas. Tech., in press, 2009.

Preusse, P., Dörnbrack, A., Eckermann, S. D., Riese, M., Schaeler, B., Bacmesister, J. T., Broutman, D., and Grossmann, K. U. Space-based measurements of stratospheric mountain waves by CRISTA, 1. Sensitivity, analysis method, and a case study, J. Geophys.Res., 107, 8178-8207, 2002.

Riese, M., Manney, G. L., Oberheide, J., Tie, X., Spang, R., and Kuell, V.: Stratospheric transport by planetary wave mixing as observed during CRISTA-2, J.Geophys. Res., 107(D23), 8179, doi:10.1029/2001JD000629, 2002.

Riese, M., Friedl-Vallon, F., Spang, R., Preusse, P., Schiller, C., Hoffmann, L., Konopka, P., Oelhalf, H., von Clarmann, T., and Höpfner, M.: GLObal limb Radiance Imager for the Atmosphere (GLORIA): Scientific objectives, Adv. Space Res., 36, 989-995, 2005.

Schaeler, B., Offermann, D., Kuell, V., Jarisch, M., Feldmann, H., and Ebel, A.: Regional and global trace gas distributions and inferred transports in the upper troposphere and lower stratosphere, J. Geophys. Res., 110(D9), D09104, doi:10.1029/2004JD004994, 2005.

Sherwood, S. C., Jung-Hyo, C., Minnis, P., and McGill, M.: Underestimation of deep convective cloud tops by thermal imagery, Geophys. Res. Lett., 31, L11102, doi:10.1029/2004GL019699, 2004.

Smith, A. K., Preusse, P., and Oberheide, J.: Middle atmosphere Kelvin waves observed in CRISTA 1 and 2 temperature and trace species, J. Geophys. Res., 107(D23), 8177, doi:10.1029/2001JD000577, 2002.

Spang, R., Griessbach, S., Höpfner, M., Dudhia, A., Hurley, J., Siddans, R., Waterfall, A., Remedios, J., and Sembhi, H.: Technical Note: Retrievability of MIPAS cloud parameter, ESA-ITT AO/15255/06/I-OL, 2008.

Spang, R. and Remedios, J. J.: Observations of a distinctive infrared spectral feature in the atmospheric spectra of polar stratospheric clouds measured by the CRISTA instrument, Geophys. Res. Lett., 30(16), 1875, doi:10.1029/2003GL017231, 2003.

Spang, R., Eidmann, G., Riese, M., Offermann, D., Preusse, P., Pfister, L., and Wang, P.-H.: CRISTA observations of cirrus clouds around the tropopause, J. Geophys. Res., 107(D23), 8174, doi:10.1029/2001JD000698, 2002.

Steppeler, J., Doms, G., Schättler, U., Bitzer, H. W., Gassmann, A., Damrath, U., and Gregoric, G.: Meso-gamma scale forecasts using the nonhydrostatic model LM, Meteorol. Atmos. Phys., 82, 75-96, 2003.

Stiller, G. P., von Clarmann, T., Bruehl, C., Fischer, H., Funke, B., Glatthor, N., Grabowski, U., Hoepfner, M., Jockel, P., Kellmann, S., Kiefer, M., Linden, A., Lopez-Puertas, M., Tsidu, G. M., Milz, M., Steck, T., and Steil, B.: Global distributions of $\mathrm{HO}_{2} \mathrm{NO}_{2}$ as observed by the Michelson Interferometer for Passive Atmospheric Sounding (MIPAS), J. Geophys. Res., 112(D9), D09314, 2007.

Stiller, G. P., von Clarmann, T., Höpfner, M., Glatthor, N., Grabowski, U., Kellmann, S., Kleinert, A., Linden, A., Milz, 
M., Reddmann, T., Steck, T., Fischer, H., Funke, B., LópezPuertas, M., and Engel, A.: Global distribution of mean age of stratospheric air from MIPAS SF6 measurements, Atmos. Chem. Phys., 8, 677-695, 2008,

http://www.atmos-chem-phys.net/8/677/2008/.

Wang, P. H., Minnis, P., Wielicki, B. A., Wong, T., Cess, R. D., Zhang, M., Vann, L. B., and Kent, G. S.: Characteristics of the 1997/1998 El Nino cloud distributions from SAGE II observations, J. Geophys. Res., 108(DI), 4009-4019, 2003.
Ward, W., Oberheide, J., Riese, M., Preusse, P., and Offermann, D.: Tidal signatures in temperature data from CRISTA 1 mission, J. Geophys. Res., 104(D13), 16391-16403, 1999.

Zhang, S. P. and Shepherd, G. G.: Extreme longitudinal disturbances in the mesosphere and thermosphere observed with the Wind Imaging Interferometer on UARS, Geophys. Res. Lett., 35, L16802, doi:10.1029/2008GL034352, 2008. 